\title{
A Novel Two-Step Approach for Retrieval of an Impacted Biliary Extraction Basket
}

\author{
Calvin H. Y. Chan, Fergal Donnellan, Godfrey C. K. Chan, and Michael F. Byrne \\ Division of Gastroenterology, Vancouver General Hospital, University of British Columbia, Vancouver, BC, Canada V5Z 1 M9 \\ Correspondence should be addressed to Calvin H. Y. Chan, calvinhychan@gmail.com
}

Received 3 May 2012; Accepted 24 July 2012

Academic Editors: I. M. Leitman and Ö. Yönem

Copyright ( 2012 Calvin H. Y. Chan et al. This is an open access article distributed under the Creative Commons Attribution License, which permits unrestricted use, distribution, and reproduction in any medium, provided the original work is properly cited.

\begin{abstract}
Biliary extraction baskets are a commonly used instrument for the removal of choledocholithiasis in endoscopic retrograde cholangiopancreatography (ERCP). Impaction of the extraction basket is a recognized complication of ERCP, and is usually the result of discrepancy between the size of bile duct stone and the diameter of the distal bile duct. Whilst mechanical lithotriptors can be used to crush the stone or break the wires of the basket to allow its release, failure of the lithotriptor device can occur. We describe the case of a 59-year-old gentleman who had an ERCP performed for choledocholithiasis. Basket impaction was encountered, and the mechanical lithotriptor failed to dislodge the stone/basket complex. A two-step technique involving balloon dilatation and forceps manipulation of the basket was applied to successfully dislodge the impacted basket. We believe this simple and safe technique should be adopted to rescue impacted biliary extraction baskets to avoid the need for potential surgical removal.
\end{abstract}

\section{Introduction}

One of the most common indications for endoscopic retrograde cholangiopancreatography (ERCP) is choledocholithiasis. Stone extraction baskets are commonly used to remove biliary tract stones. One recognized complication of stone extraction is impaction of the extraction basket in the bile duct, a result of stone to distal duct size discrepancy. Whilst some baskets have a release mechanism to reduce the risks of impaction, other baskets rely on the use of an intra-or extraendoscopic mechanical lithotriptor to either crush the stone or break the wires of the basket to allow its release. The mechanical lithotriptor is often considered a final resort before surgical removal of the impacted basket and stone complex is considered necessary. We describe a case of an impacted extraction basket removed by a novel technique using step and balloon dilatation combined with rat-tooth forceps removal, after failure of deployment of a mechanical lithotriptor.

\section{Case Report}

A 59-year-old gentleman with no other significant background medical history presented to the emergency department of Vancouver General Hospital with a 12-hour history of painful jaundice. He was afebrile and there were no clinical features of sepsis upon presentation. Liver function tests demonstrated a bilirubin of $134 \mu \mathrm{mol} / \mathrm{L}$, GGT of $677 \mathrm{U} / \mathrm{L}$, and ALT of $239 \mathrm{U} / \mathrm{L}$. His inflammatory markers were normal. A transabdominal ultrasound demonstrated mild intrahepatic duct dilatation with a dilated common bile duct measuring $10 \mathrm{~mm}$ in diameter and evidence of a $10 \mathrm{~mm}$ stone in the mid CBD (Figure 1). The gallbladder was partially distended with no wall thickening or pericholecystic fluid and indefinite for cholecystolithiasis.

A diagnosis of obstructive jaundice secondary to choledocholithiasis was made and the patient proceeded to an ERCP with planned removal of the sonographically visualized stone. Biliary cannulation was difficult. A needle knife fistulotomy was required to facilitate biliary access, and subsequent cholangiogram demonstrated a $10 \mathrm{~mm}$ bile duct with an ill-defined $8 \mathrm{~mm}$ filling defect in the mid duct. The fistulotomy orifice was extended with a sphincterotome, and a $25 \mathrm{~mm}$ extraction basket (The Web extraction basket, Cook Inc, Winston-Salem, NC, USA) was used to extract the stone. Surprisingly, despite the apparent size compatibility of the stone with distal duct and sphincterotomised orifice 


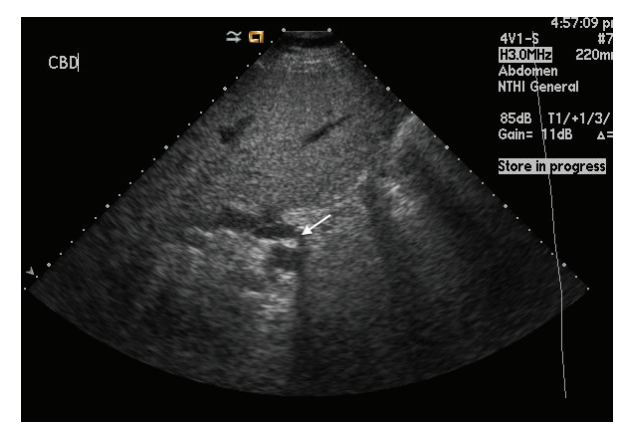

Figure 1: Transabdominal ultrasound of common bile duct (CBD) with CBD stone (arrow) and associated posterior acoustic shadowing.

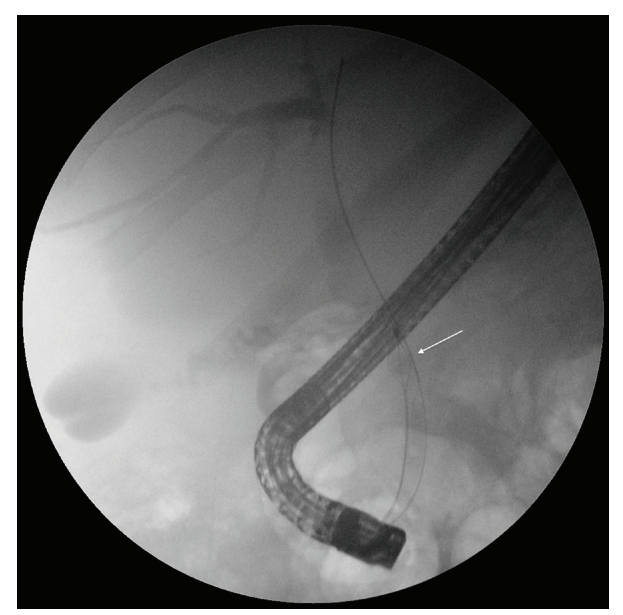

FIGURE 2: ERCP demonstrating the biliary extraction basket around a stone (arrow) within the CBD.

(Figure 2), the basket became impacted within the intraduodenal portion of the bile duct.

The plastic sheath covering the basket wire was cut exposing the free wires of the basket, and a mechanical extraendoscopic lithotriptor was used (Soehendra lithotriptor, Cook Inc, Winston-Salem, NC, USA). Upon cranking the lithotriptor, the wires fractured at the handle, outside the oral cavity. The duodenoscope (JF 180, Olympus Optical Co Ltd, Toyo, Japan) was then reinserted into the duodenum and biliary cannulation was reattempted around the basket (Figure 3). However, due to the local edema, no instruments beside a guidewire were able to be advanced beyond the stone/basket complex. A second attempt at mechanical lithotripsy was performed with the use of a shorter Soehendra mechanical lithotriptor metallic sheath, but again, the wire fractured a second time at the handle. A decision was made to reattempt ERCP 48 hours later to allow the local edema to settle. The procedure was abandoned, the basket wire secured with dressing forceps and surgical tape outside the oral cavity, and the patient placed on prophylactic antibiotics.

The patient remained stable and ERCP was reattempted. Cannulation was reattempted with a sphincterotome (Dreamtome, Boston Scientific, Natick, Mass, USA),

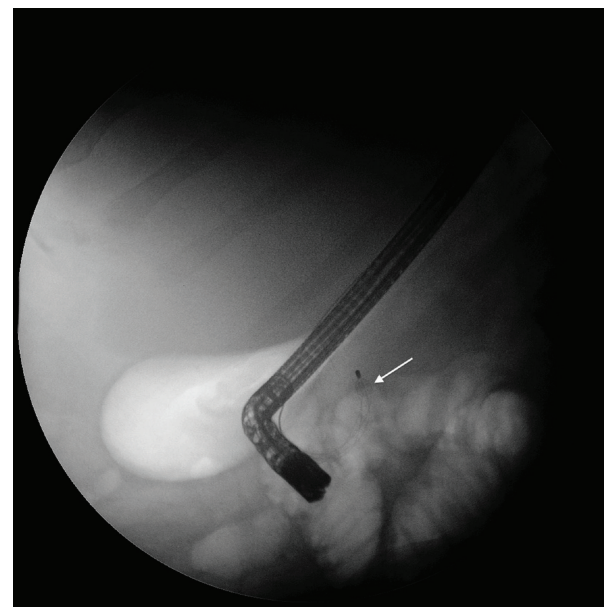

Figure 3: Basket/stone complex (arrow) lodged in the distal CBD after attempted mechanical lithotripsy.

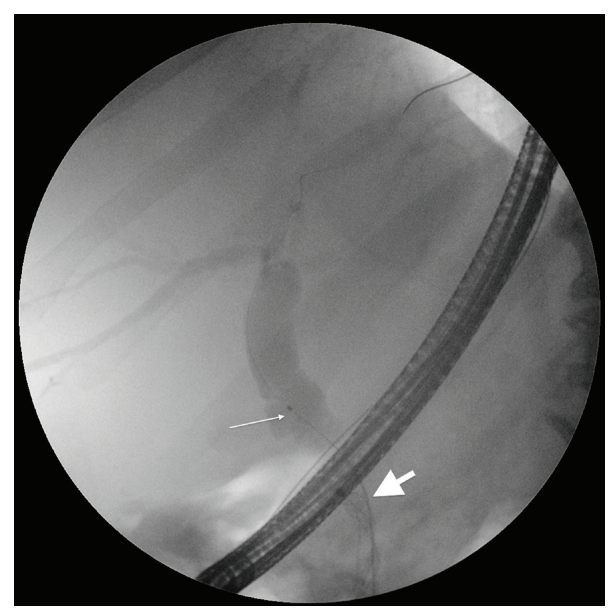

FIGURE 4: Insertion of a wire guided $8.5 \mathrm{Fr}$ dilating catheter (thin arrow) beside the basket/stone complex (thick arrow) in the CBD.

but once again only the guidewire was able to be advanced beyond the basket/stone complex. An 8.5 Fr biliary dilating catheter (Fusion Biliary Dilation Catheter, Wilson-Cook, Winston-Salem, NC, USA) was able to be introduced over the guidewire (Figure 4). This allowed a $12 \mathrm{~mm}$ dilating balloon (CRE Balloon, Boston Scientific, Natick, MA, USA) to be deployed at the level of the impacted basket (Figure 5). We then used rat-tooth forceps (Olympus Tokyo, Japan) to grasp the struts of the basket. The basket was easily dislodged. A 7 Fr $7 \mathrm{~cm}$ double pigtail stent was subsequently inserted as a precautionary measure against ductal trauma (Figure 6) and the patient was discharged the next day. He returned one month later with an uncomplicated clearance of his bile duct with an extraction balloon and removal of the stent.

\section{Discussion}

Biliary extraction baskets are made from metal wires and are available in a variety of sizes and configurations. Basket 


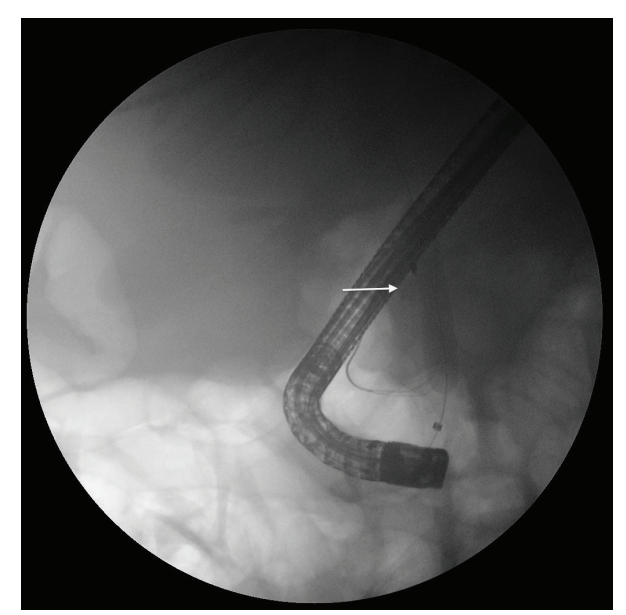

FIGURE 5: Inflation of a $12 \mathrm{~mm}$ dilating balloon beside the stone/ basket complex (arrow) in the distal CBD.

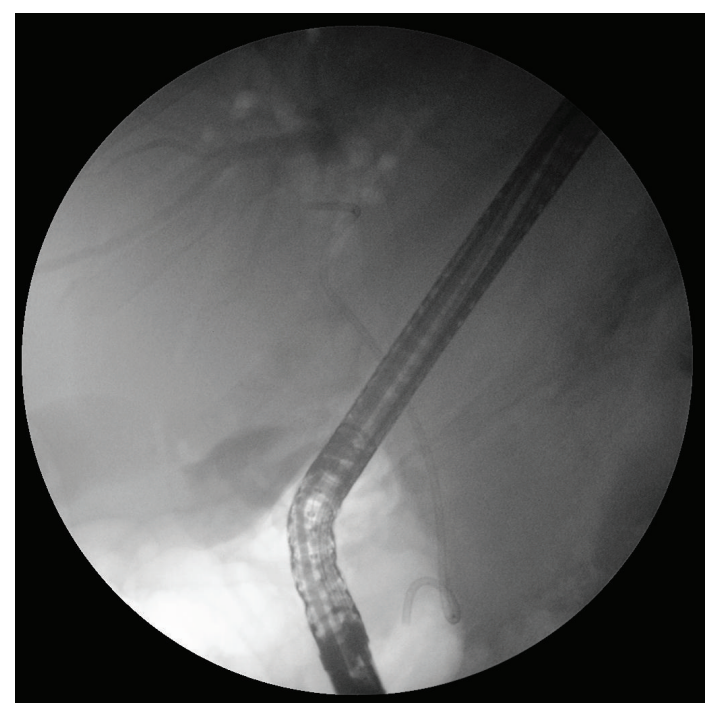

FIgURE 6: Double pigtail biliary stent within the CBD after basket removal.

impaction is an uncommon but recognized complication of ERCP stone extraction, and represents a medical emergency. Whilst some baskets have a built-in safety mechanism to break upon excess force of closure, most baskets require an external crushing sheath such as the Soehendra lithotriptor to either crush the stone or break the basket wire to retrieve the device. Both external and "through the scope" lithotriptors are available $[1,2]$. To avoid surgical removal, alternative techniques described include awaiting for spontaneous passage [3], the use of extracorporeal shockwave lithotripsy [4-6], intracorporeal electrohydraulic lithotriptor [7], extending the sphincterotomy with a needle knife [8], and tipping the basket tip using a second basket [9].

The use of rat-tooth forceps to maneuver the basket struts to slide beside the stone has been described [10], but this alone may be ineffective in a less-distended duct with a heavily impacted basket. Just as balloon sphincteroplasty has aided removal of large biliary stones [11], we describe a technique here combining two-proven modalities to safely remove an impacted basket. The purpose of the graduated dilating catheter was to allow a dilating balloon to be advanced beside the stone/basket complex. By dilating the sphincter and the distal duct, this allows the basket struts to be easily maneuvered by the rat-tooth forceps to slide beside the stone. The remaining basket should subsequently have adequate space to be retrieved. This simple combination of steps should be considered in patients with impacted baskets before consideration of surgical removal.

\section{Conflict of Interests}

The authors declare that they have no conflict of interests.

\section{References}

[1] M. Matsushita, H. Takakuwa, Y. Matsubayashi et al., "Through-the-endoscope technique for retrieval of impacted biliary baskets with trapped stones," American Journal of Gastroenterology, vol. 99, no. 6, pp. 1198-1199, 2004.

[2] P. Draganov and J. T. Cunningham, "Novel "through-theendoscope" technique for removing biliary stones trapped in a retrieval basket," Endoscopy, vol. 34, no. 2, p. 176, 2002.

[3] B. Neuhaus and L. Safrany, "Complications of endoscopic sphincterotomy and their treatment," Endoscopy, vol. 13, no. 5, pp. 197-199, 1981.

[4] S. M. Schutz, C. Chinea, and P. Friedrichs, "Successful endoscopic removal of a severed, impacted dormia basket," American Journal of Gastroenterology, vol. 92, no. 4, pp. 679-681, 1997.

[5] W. G. Payne, J. G. Norman, and H. Pinkas, "Endoscopic basket impaction," American Surgeon, vol. 61, no. 5, pp. 464-467, 1995.

[6] M. Merrett and P. Desmond, "Removal of impacted endoscopic basket and stone from the common bile duct by extracorporeal shock waves," Endoscopy, vol. 22, no. 2, p. 92, 1990.

[7] J. Sheridan, T. M. Williams, E. Yeung, C. S. Ho, and W. Thurston, "Percutaneous transhepatic management of an impacted endoscopic basket," Gastrointestinal Endoscopy, vol. 39, no. 3, pp. 444-446, 1993.

[8] M. Borgaonkar, "Impacted biliary basket," Gastrointestinal Endoscopy, vol. 62, no. 3, p. 474, 2005.

[9] P. Ranjeev and K. L. Goh, "Retrieval of an impacted Dormia basket and stone in situ using a novel method," Gastrointestinal Endoscopy, vol. 51, no. 4, pp. 504-506, 2000.

[10] S. Ryozawa, H. Iwano, K. Taba, M. Senyo, and I. Sakaida, "Successful retrieval of an impacted mechanical lithotripsy basket: a case report," Digestive Endoscopy, vol. 22, no. 1, supplement, pp. S111-S113, 2010.

[11] A. Maydeo and S. Bhandari, "Balloon sphincteroplasty for removing difficult bile duct stones," Endoscopy, vol. 39, no. 11, pp. 958-961, 2007. 


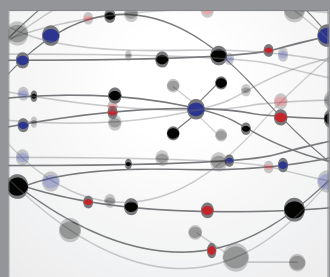

The Scientific World Journal
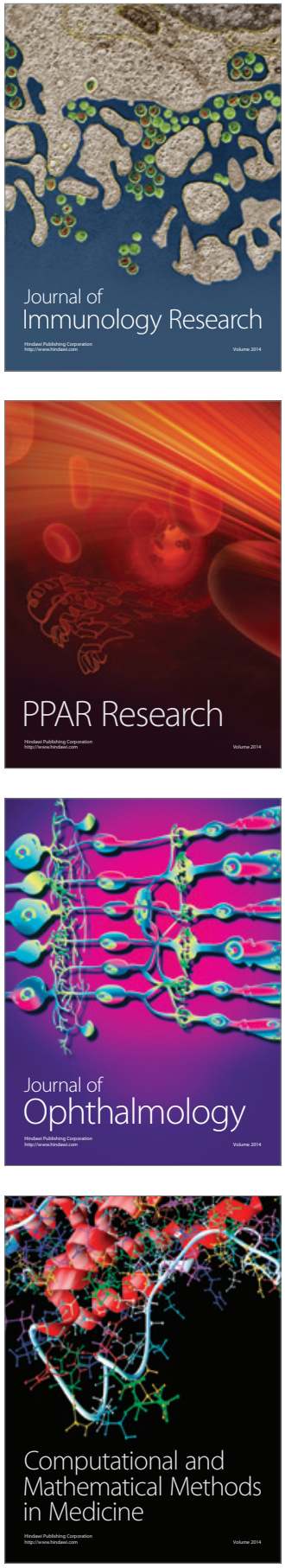

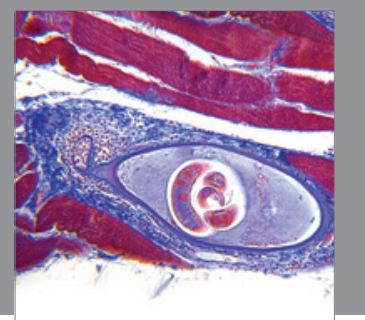

Gastroenterology

Research and Practice
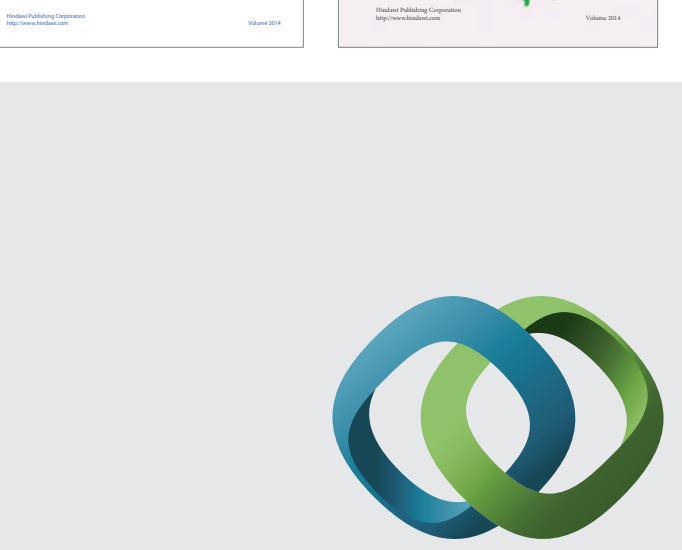

\section{Hindawi}

Submit your manuscripts at

http://www.hindawi.com
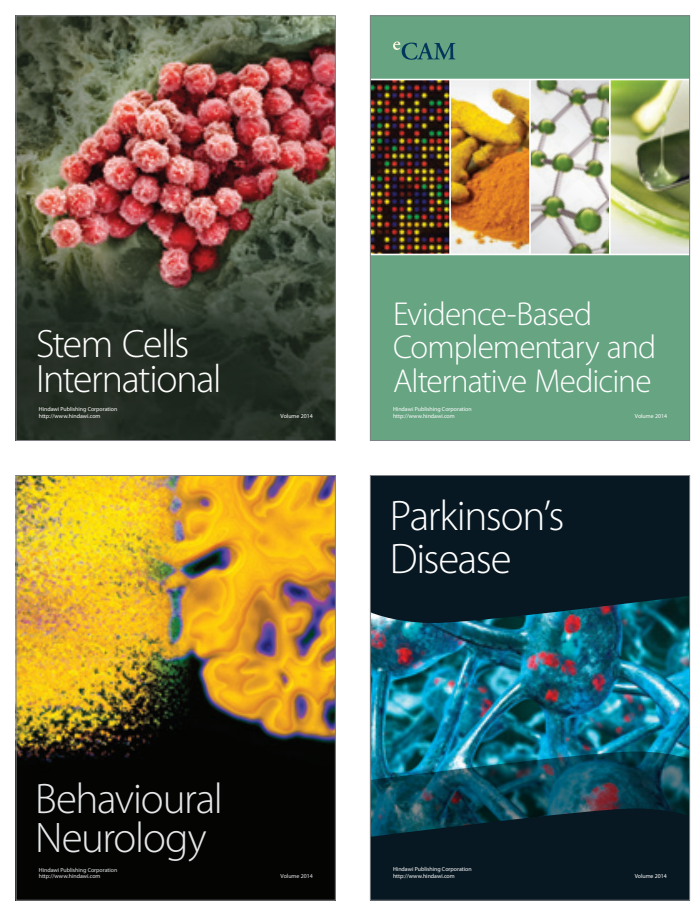

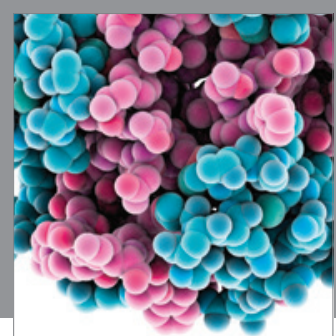

Journal of
Diabetes Research

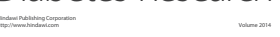

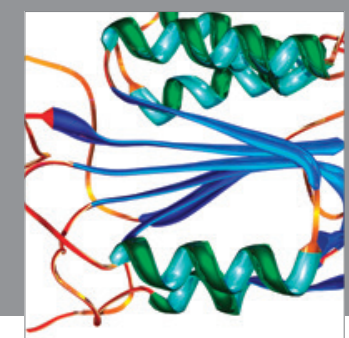

Disease Markers
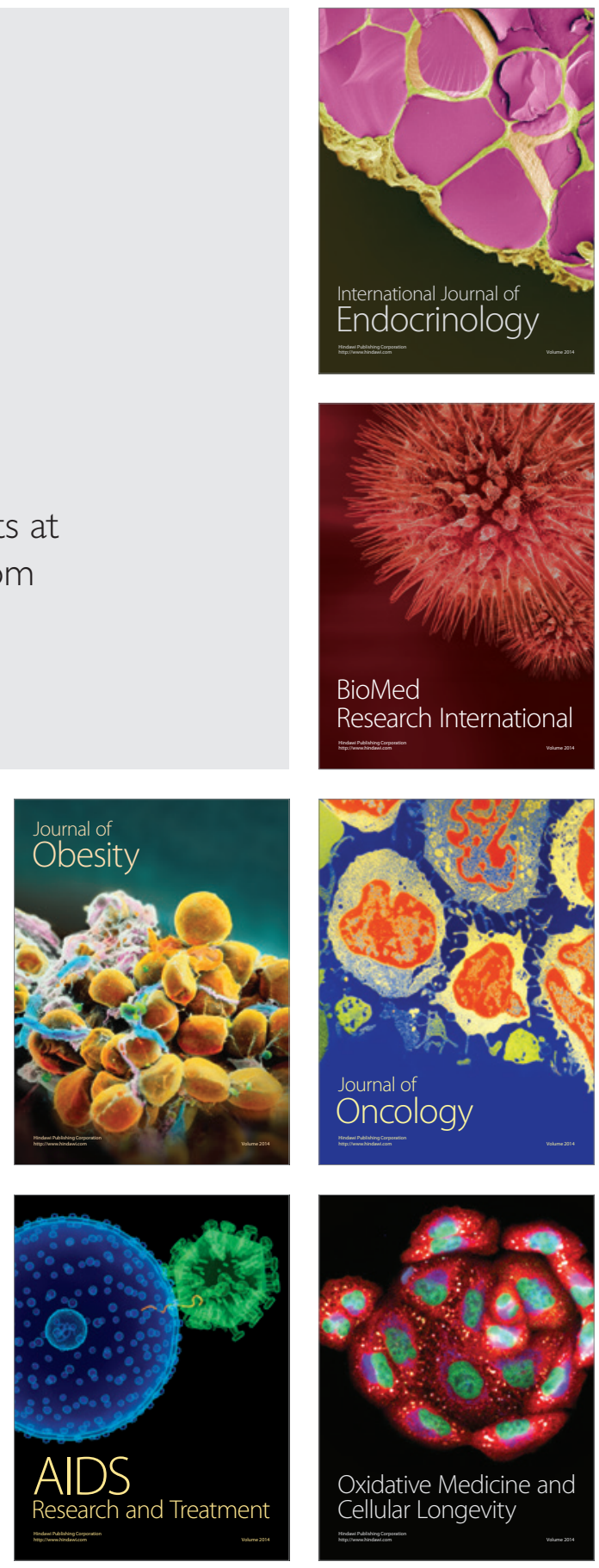